\title{
Psychiatric disorders in male prisoners who made near-lethal suicide attempts: case-control study
}

\author{
Adrienne Rivlin, Keith Hawton, Lisa Marzano and Seena Fazel
}

\section{Background}

Although male prisoners are five times more likely to die by suicide than men of a similar age in the general population, the contribution of psychiatric disorders is not known.

\section{Aims}

To investigate the association of psychiatric disorders with near-lethal suicide attempts in male prisoners.

\section{Method}

A matched case-control study of 60 male prisoners who made near-lethal suicide attempts (cases) and 60 prisoners who had never carried out near-lethal suicide attempts in prison (controls) was conducted. Psychiatric disorders were identified with the Mini International Neuropsychiatric Interview (MINI), and information on sociodemographic characteristics and criminal history was gathered using a semi-structured interview.

\section{Results}

Psychiatric disorders were present in all cases and $62 \%$ of controls. Most current psychiatric disorders were associated with near-lethal suicide attempts, including major depression (odds ratio $(\mathrm{OR})=42.0,95 \% \mathrm{Cl} 5.8-305)$, psychosis $(\mathrm{OR}=15.0$ 95\% Cl 2.0-113), anxiety disorders (OR $=6.0,95 \% \mathrm{Cl} 2.3-15.5)$ and drug misuse $(\mathrm{OR}=2.9,95 \% \mathrm{Cl} 1.3-6.4)$. Lifetime psychiatric disorders associated with near-lethal attempts included recurrent depression and psychoses. Although cases were more likely than controls to meet criteria for antisocial personality disorder, the difference was not statistically significant. Comorbidity was also significantly more common among cases than controls for both current and lifetime disorders.

\section{Conclusions}

In male prisoners, psychiatric disorders, especially depression, psychosis, anxiety and drug misuse, are associated with near-lethal suicide attempts, and hence probably with suicide.

\section{Declaration of interest}

None.
Reducing the incidence of suicide by prisoners is part of national strategies for suicide prevention in the USA, ${ }^{1} \mathrm{UK},{ }^{2}$ Ireland ${ }^{3}$ and other countries, ${ }^{4}$ and is highlighted in a recent World Health Organization statement on mental health in prisons. ${ }^{5}$ Relative to age-adjusted rates in the general population, suicide rates in male prisoners are five times higher in England and Wales, ${ }^{6}$ and large proportionate excesses have been found in the USA ${ }^{7}$ and some mainland European countries. ${ }^{8}$ Potentially modifiable factors have been the focus of suicide prevention guidelines in prisons, ${ }^{9,10}$ although there has been little attention to specific psychiatric disorders. A recent systematic review showed that clinical factors have strong associations with suicide in prison, but which diagnoses and their relative contributions were uncertain. ${ }^{11}$ Part of the reason for this is that investigating risk factors for prison suicide has principally been based on examination of official records, or use of the psychological autopsy approach, which aims to build a retrospective picture of the deceased's mental state at the time of death in order to develop a profile of the prisoner. ${ }^{12}$ As this method relies primarily on medical records for information on clinical factors, it is limited by the quality of these. ${ }^{13-15}$

In this study, we addressed this limitation by assessing psychiatric disorders in male prisoners who made near-lethal suicide attempts and comparing them with those of a matched control group of prisoners who had never made a similar attempt in prison. ${ }^{16}$ The validity of the near-lethal method is supported by two pieces of evidence. First, survivors of medically serious suicide attempts are epidemiologically similar to individuals who die by suicide. $^{17,18}$ Second, individuals who have made a medically serious suicide attempt are twice as likely as other people who have attempted suicide to subsequently complete suicide. ${ }^{19}$ Furthermore, the near-lethal method has been piloted in prisons. ${ }^{20}$ However, the pilot study only included 15 male prisoners, there was no control group and psychiatric morbidity was not investigated.

\section{Method}

\section{Participating prisons}

We requested information from the Ministry of Justice Safer Custody and Offender Policy Group on prisons within 100 miles of Oxford that had relatively high rates of serious suicide attempts and completed suicides. Nineteen prisons were identified, including three young offenders' institutes (prisoners aged 18-21), three Category A (maximum security) prisons, 12 Category B prisons (establishments for those who do not require maximum security but for whom escape must be made difficult) and one Category $\mathrm{C}$ prison (for prisoners who cannot be housed in open conditions but who are unlikely to try to escape).

\section{Participant identification}

Near-lethal suicide attempts were defined as acts that could have been lethal had it not been for intervention or chance, and/or involved methods that are associated with a reasonably high chance of death. ${ }^{21}$ Detailed criteria were developed to aid prison officers refer suitable cases to the study (Appendix). The criteria are based on the physical danger and consequences of the act, an approach that is in line with that used in previous investigations of near-lethal suicide attempts in the community. ${ }^{21}$ They intentionally do not include suicidal intent. This is because basing the criteria only on the lethality of the act includes in the study both those with high suicidal intent and those whose actions may have very nearly caused death but may not have been motivated by suicidal intentions. Such cases would be recognised 
by most researchers as being within a broad conceptualisation of suicide.

Cases were interviewed within 4 weeks of the suicide attempt. Controls were prisoners who had not made a near-lethal suicide attempt while in prison. They were matched with cases by age (5 years older or younger) and by type/category of prison. Identification of controls was done randomly from the Ministry of Justice's daily list of prisoners using these two matching criteria. All participants were aged 18 years and over.

Prisoners making a near-lethal suicide attempt were excluded from the study if they declined to take part (15 individuals), could not speak English (8), were considered too dangerous (4) or too seriously mentally ill (1), or because staff shortages or absences meant that the 4-week time limit within which an interview had to be conducted had been missed (6). A further eight prisoners were released from prison or transferred to a non-participating prison before an interview could be arranged. Those included in the case group were significantly more likely than those excluded to be White $(52 / 60(87 \%)$ v. $25 / 42(60 \%)$, odds ratio $(\mathrm{OR})=4.4$, 95\% CI 1.7-11.6) and to be on a life sentence (13/39 (33\%) v. 2/23 $(9 \%) \quad \mathrm{OR}=5.1,95 \%$ CI 1.0-24.9). Other recorded sociodemographic and criminological characteristics did not differ significantly between the included and excluded prisoners.

\section{Interviews}

Following training in use of the instruments and questionnaires employed in the research, and piloting at a large adult male local prison, one of the authors (A.R.) conducted semi-structured face-to-face interviews with 60 cases and 60 controls. A total sample size of 120 was calculated to provide sufficient power to determine important differences in psychiatric characteristics. After participants' written consent had been obtained, the interviews took place in private in the prison and lasted for 90-120 min. Participants were offered support both before and after the interviews from a prison officer, chaplain, Samaritan, Listener (trained peer support) or psychologist.

Sociodemographic and criminal history information was gathered using an adapted version of a structured questionnaire used in the Oxford Monitoring System for Attempted Suicide. ${ }^{22}$ The following information regarding a participant's medical and psychiatric history was collected: history of in-patient or out-patient psychiatric treatment, current psychotropic medication, current contact with a mental health professional (including a psychiatrist, psychologist, counsellor or community psychiatric nurse), and previous self-harm (with and without suicidal intent). For cases, we also administered the Beck Suicide Intent Scale (SIS) to assess severity of suicidal intent associated with near-lethal acts. ${ }^{23}$

Psychiatric morbidity was assessed with the Mini International Neuropsychiatric Interview (MINI), ${ }^{24}$ which includes Axis I (psychiatric) and II (personality) disorders for DSM-IV ${ }^{25}$ and ICD $-10^{26}$ diagnoses. The MINI has been demonstrated to have good to very good validity, reliability (interrater and test-retest), and sensitivity and specificity indices. ${ }^{27-29}$ When compared with the Structured Clinical Interview for DSM-III-R (SCID), ${ }^{30}$ the MINI had good to very good kappa values (apart from current drug dependence, which was the only diagnosis with a $\kappa<0.5$ ). Except for dysthymia, obsessive-compulsive disorder, and current drug dependence, sensitivity was 0.70 or above for all disorders. For major depression, lifetime mania, current and lifetime panic disorder, lifetime agoraphobia, lifetime psychotic disorder, anorexia and post-traumatic stress disorder (PTSD), positive predictive values have been found to be above 0.75. Other advantages of the MINI include its relatively brief administration time (15-20 min) and ease of use. ${ }^{28,29}$ The MINI has also been used in prisons. ${ }^{31-33}$ However, previous research in prisoners ${ }^{33}$ and our pilot work suggested that the MINI may overdiagnose certain disorders. We therefore made the following modifications: a diagnosis of mania (current or lifetime) was only made when prisoners met criteria for elation/expansiveness (i.e. irritable mood alone was insufficient to reach a diagnosis); and a diagnosis of obsessive-compulsive disorder was dependent on meeting criteria for both obsessions and compulsions.

\section{Ethical approval}

The study had ethical approval from the Central Office for Research Ethics Committees (Ethics number 06/MRE12/83), and the Prison Service (Reference PG 2006 063).

\section{Statistical analyses}

All analyses were conducted using the Statistical Package for the Social Sciences (SPSS, Version 15.0 for Windows) and STATA (Version 9.0 for Windows). A 95\% $(P<0.05)$ significance level was adopted. In the results, unless otherwise specified, denominators for both cases and controls are 60 . Odds ratios, 95\% confidence intervals and associated $P$-values for analyses of categorical factors were calculated using McNemar's test to account for matching of cases and controls. For continuous data, paired sample $t$-tests and Wilcoxon signed ranks tests (for non-normally distributed data) were used.

Possible confounders (ethnicity, marital status, prior employment, educational qualifications, index offence, remand status, previous prison spells, and sentence length greater than 18 months) were assessed using conditional logistic regression. We examined whether confounders were each independently associated with having made a near-lethal attempt in prison and with specific psychiatric disorders. Confounders were then introduced and left in the model if they altered the odds ratio by more that $10 \% .{ }^{34,35}$ No confounder fulfilled both these criteria.

We looked at risk of near-lethal suicide attempts according to diagnostic subgroups using conditional logistic regression (as the data were matched on age and prison type/category). Where the number of discordant pairs of cases and controls was less than 10, we do not report odds ratios.

\section{Results}

\section{Near-lethal suicide attempts}

Hanging or ligaturing accounted for two-thirds $(n=40,67 \%)$ of the near-lethal suicide attempts. There were also $12(20 \%)$ incidents of severe cutting, 3 (5\%) self-asphyxiations, 3 (5\%) overdoses of paracetamol and/or ibuprofen, 1 (2\%) ingestion of foreign objects (plastic knives) and $1(2 \%)$ self-immolation.

All but one incident $(59,98 \%)$ took place in the prisoners' own cells. Most of these were in the prisioners' normal location $(46,77 \%)$, ten $(17 \%)$ were in segregation units and four $(7 \%)$ were in the prison healthcare centre. The majority of prisoners in the case group were not identified as 'at risk' at the time of the incident. Only 24 (40\%) were on an open ACCT (Assessment, Care in Custody and Teamwork) document, which is the formal system for registering and monitoring prisoners thought to be at risk of suicide and self-harm in prisons in England and Wales. ${ }^{36}$ Over one-third $(18 / 49,37 \%)$ of individuals in the case group were withdrawing from drugs or alcohol at the time of the incident. The mean Beck Suicide Intent score was 19.0 (s.d. $=5.4$, range 2-29). By comparison, the mean score for males assessed at a general hospital in England following an incident of self-harm or self-poisoning has been reported to be $10.6 .{ }^{37}$ 


\section{Sociodemographic and criminological variables}

Near-lethal suicide attempts were associated with being White, having no educational qualifications, having been in prison previously, having been imprisoned for less than 30 days and having been in the current prison for less than 30 days (Table 1).

\section{Psychiatric history}

Near-lethal suicide attempts were associated with a history of psychiatric treatment and self-harm (Table 1).

\section{Current psychiatric disorder}

Psychiatric disorders were present in all cases and $62 \%$ of controls (Table 2). Excluding substance use disorders, 58 (97\%) cases and $21(35 \%)$ controls had a psychiatric disorder $(\mathrm{OR}=38.0,95 \% \mathrm{CI}$ 5.2-277). Comorbidity of disorders was particularly prevalent in cases. Most psychiatric diagnoses were associated with near-lethal suicide attempts, especially depression, psychosis, panic disorder and any anxiety disorder. Alcohol misuse was related to near-lethal suicide attempts but this association did not reach statistical significance.

\section{Lifetime psychiatric disorders}

Recurrent depression and all psychoses were associated with nearlethal suicide attempts (Table 3 ). Although cases were more likely than controls to meet criteria for antisocial personality disorder, the difference was not statistically significant.

\section{Psychiatric treatment at the time of the interview}

Significantly more cases than controls were receiving psychiatric treatment and psychotropic medication at the time of the interview (Table 4). However, there was a discrepancy between the number of cases diagnosed using the MINI with a current episode of major depression $(52,87 \%)$ and those being prescribed antidepressants $(22,37 \%)$.

\section{Discussion}

We used a standardised diagnostic instrument in an interview study of 120 male prisoners in 19 prisons in England to investigate associations with near-lethal suicide attempts. We found that clinical factors were strongly associated with near-lethal suicide attempts, particularly current and recurrent depression, current and lifetime psychosis, current anxiety disorders and previous self-harm.

\section{Current psychiatric disorders}

Cases were significantly more likely to be suffering from any mood disorder (particularly major depression) than controls, anxiety (notably panic, PTSD and social anxiety), psychotic disorders, and to have comorbid disorders. In the general population, completed suicide is also associated with these disorders. ${ }^{38}$ However, although alcohol misuse is a risk factor for suicide in the general population, ${ }^{39}$ it was not strongly associated with nearlethal suicide attempts in this prisoner population. In previous research on suicide by prisoners, similar associations were identified with any psychiatric diagnosis in an Austrian case-control study $^{13}$ and with psychosis in a recent US investigation. ${ }^{40}$ However, the findings on the role of comorbidity and anxiety disorders have not, to our knowledge, been previously reported. ${ }^{11}$

After depression, alcohol and drug disorders, PTSD was the most prevalent disorder in the cases, and was also associated with a near-lethal suicide attempt. Post-traumatic stress disorder has received little attention in suicide research in prisons ${ }^{41}$ and, considering its potential treatability, further research investigating its role in suicide risk is warranted.

\section{Lifetime psychiatric disorders}

Apart from hypomania, all lifetime Axis I diagnoses, and comorbidity, were associated with near-lethal suicide attempts in

\begin{tabular}{|c|c|c|c|c|c|c|c|}
\hline \multirow[b]{2}{*}{ Variable } & \multicolumn{2}{|c|}{ Cases $n=60$} & \multicolumn{2}{|c|}{ Controls $n=60$} & \multirow[b]{2}{*}{$\chi^{2}$} & \multirow[b]{2}{*}{ OR $(95 \% \mathrm{Cl})$} & \multirow[b]{2}{*}{$P$} \\
\hline & $n$ & (\%) & $n$ & $(\%)$ & & & \\
\hline \multirow{2}{*}{\multicolumn{8}{|c|}{$\begin{array}{l}\text { Sociodemographic } \\
\text { Age (years) }\end{array}$}} \\
\hline & & & & & & & \\
\hline $18-21$ & 11 & (18) & 10 & (17) & & & \\
\hline $22-29$ & 20 & (33) & 21 & (35) & & & \\
\hline 30-39 & 22 & (37) & 17 & (28) & & & \\
\hline 40-49 & 5 & (8) & 11 & (18) & & & \\
\hline $50+$ & 2 & (3) & 1 & $(2)$ & & & \\
\hline White ethnicity $v$. Black and minority ethnic & 52 & (87) & 42 & (70) & & $2.7(1.0-6.8)$ & 0.040 \\
\hline Single $e^{a}$ & 41 & (68) & 46 & (77) & & $0.7(0.3-1.5)$ & 0.321 \\
\hline Parent or guardian of children & 35 & (58) & 31 & (52) & & $1.3(0.6-2.8)$ & 0.451 \\
\hline Educational qualifications (none $v$. any) & 21 & (35) & 11 & (18) & & $2.4(1.0-5.9)$ & 0.048 \\
\hline Unemployed $^{\mathrm{b}}$ & 35 & (58) & 29 & (48) & & $1.6(0.7-3.3)$ & 0.261 \\
\hline \multicolumn{8}{|l|}{ Criminological } \\
\hline Previous prison spell(s) & 54 & (90) & 40 & (67) & & $4.5(1.5-13.3)$ & 0.007 \\
\hline Remand status & 21 & (35) & 12 & $(20)$ & & $2.3(0.9-5.6)$ & 0.068 \\
\hline Less than 30 days since being imprisoned & 17 & (28) & 1 & (2) & & $17.0(2.3-127)$ & 0.006 \\
\hline Less than 30 days in current prison & 25 & (42) & 1 & (2) & & $25.0(3.4-185)$ & 0.002 \\
\hline \multicolumn{8}{|l|}{ Psychiatric history } \\
\hline Previous psychiatric in-patient treatment & 20 & (33) & 3 & (5) & & $9.5(2.2-40.8)$ & 0.002 \\
\hline Previous psychiatric out-patient treatment & 21 & (35) & 5 & (8) & & $5.0(1.7-14.6)$ & 0.003 \\
\hline Previous self-harm ${ }^{c}$ in prison ${ }^{d}$ & 41 & (68) & 5 & (8) & 36.0 & & $<0.0001$ \\
\hline Previous self-harm ${ }^{\mathrm{C}}$ outside prison & 38 & (63) & 20 & (33) & & $3.3(1.5-7.2)$ & 0.004 \\
\hline
\end{tabular}


prison. Antisocial personality disorder is a risk factor for suicide in the general population, ${ }^{42}$ and we found a non-significant trend to this effect in prisoners who had made near-lethal suicide attempts. This is in line with previous research findings regarding the association between antisocial personality disorder and suicidal behaviour in prisoners ${ }^{43}$ and probably reflects the high frequency of this disorder in the general prison population.

\begin{tabular}{|c|c|c|c|c|c|c|}
\hline \multirow[b]{2}{*}{ Disorder } & \multicolumn{2}{|c|}{ Cases $n=60$} & \multicolumn{2}{|c|}{ Controls $n=60$} & \multirow[b]{2}{*}{ Odds ratio $(95 \% \mathrm{Cl})$} & \multirow[b]{2}{*}{$P$} \\
\hline & $n$ & (\%) & $n$ & $(\%)$ & & \\
\hline \multicolumn{7}{|l|}{ Mood disorders } \\
\hline Major depression & 52 & (87) & 11 & (18) & $42.0(5.8-305)$ & $<0.001$ \\
\hline With melancholic features & 43 & (71) & 9 & (15) & $35.0(4.8-255)$ & $<0.001$ \\
\hline Dysthymia $^{a}$ & 2 & (3) & 1 & (2) & & \\
\hline Mania ${ }^{\mathrm{b}}$ & 0 & (0) & 0 & (0) & & \\
\hline Hypomania $^{\mathrm{b}}$ & 0 & (0) & 1 & (2) & & \\
\hline Any & 54 & (90) & 13 & (22) & $42.0(5.8-305)$ & $<0.001$ \\
\hline \multicolumn{7}{|l|}{ Anxiety disorders } \\
\hline Panic & 11 & (18) & 2 & (3) & $10.0(1.3-78)$ & 0.028 \\
\hline Agoraphobia $^{a}$ & 6 & (10) & 2 & (3) & & \\
\hline Social anxiety & 19 & (32) & 2 & (3) & $9.5(2.2-40.8)$ & 0.002 \\
\hline Generalised & 18 & (30) & 1 & (2) & & \\
\hline Non-generalised & 1 & (2) & 1 & (2) & & \\
\hline Obsessive-compulsive ${ }^{a}$ & 4 & (7) & 2 & (3) & & \\
\hline Post-traumatic stress & 21 & (35) & 3 & (5) & $7.0(2.1-23.5)$ & 0.002 \\
\hline Generalised anxiety ${ }^{a}$ & 1 & (2) & 3 & (5) & & \\
\hline Any & 37 & (62) & 12 & (20) & $6.0(2.3-15.5)$ & $<0.001$ \\
\hline \multicolumn{7}{|l|}{ Substance use disorders } \\
\hline Alcohol & 22 & (37) & 14 & (23) & $1.9(0.8-4.2)$ & 0.123 \\
\hline Drug & 42 & (70) & 27 & (45) & $2.9(1.3-6.4)$ & 0.010 \\
\hline Any & 46 & (77) & 31 & (52) & $3.5(1.4-8.7)$ & 0.007 \\
\hline \multicolumn{7}{|l|}{ Psychotic disorders } \\
\hline With mood disorder ${ }^{b}$ & 4 & (7) & 0 & (0) & & \\
\hline Without mood disorder & 11 & (18) & 1 & (2) & $11.0(1.4-85)$ & 0.022 \\
\hline Any & 15 & (25) & 1 & (2) & $15.0(2.0-113)$ & 0.009 \\
\hline \multicolumn{7}{|l|}{ Eating disorders } \\
\hline Anorexia $^{b}$ & 0 & (0) & 0 & (0) & & \\
\hline Anorexia (binge eating/purging type) & 1 & (2) & 0 & (0) & & \\
\hline Bulimia $^{\mathrm{b}}$ & 1 & (2) & 0 & (0) & & \\
\hline Any ${ }^{\mathrm{b}}$ & 2 & (3) & 0 & (0) & & \\
\hline Any current disorder ${ }^{\mathrm{b}}$ & 60 & (100) & 37 & (62) & & \\
\hline $2+$ current disorders & 52 & $(87)$ & 20 & (33) & $17.0(4.1-70)$ & $<0.001$ \\
\hline $3+$ current disorders & 40 & (67) & 8 & (13) & $9.0(3.2-25.3)$ & $<0.001$ \\
\hline $4+$ current disorders & 27 & (45) & 3 & (5) & $9.0(2.7-29.7)$ & $<0.001$ \\
\hline
\end{tabular}

\begin{tabular}{|c|c|c|c|c|c|c|}
\hline \multirow[b]{2}{*}{ Disorder } & \multicolumn{2}{|c|}{ Cases $n=60$} & \multicolumn{2}{|c|}{ Controls $n=60$} & \multirow[b]{2}{*}{ OR $(95 \% \mathrm{Cl})$} & \multirow[b]{2}{*}{$P$} \\
\hline & $n$ & $(\%)$ & $n$ & (\%) & & \\
\hline \multicolumn{7}{|l|}{ Mood disorders } \\
\hline Major depression & 30 & (50) & 6 & (10) & $9.0(2.7-29.7)$ & $<0.0001$ \\
\hline Mania & 16 & (27) & 5 & (8) & $3.8(1.2-11.3)$ & 0.019 \\
\hline Hypomania & 8 & (13) & 4 & (7) & $2.0(0.6-6.6)$ & 0.258 \\
\hline Any & 41 & (68) & 13 & (22) & $5.0(2.2-11.3)$ & $<0.0001$ \\
\hline \multicolumn{7}{|l|}{ Psychotic disorders } \\
\hline With mood disorder ${ }^{\mathrm{a}}$ & 4 & (7) & 2 & (3) & & \\
\hline Without mood disorder & 13 & (22) & 1 & (2) & $13.0(1.7-99)$ & 0.013 \\
\hline Any & 17 & (28) & 3 & (5) & $8.0(1.8-34.8)$ & 0.006 \\
\hline Any lifetime disorder & 47 & (78) & 16 & (27) & $5.4(2.4-12.2)$ & $<0.0001$ \\
\hline 2+ lifetime disorders & 18 & (30) & 2 & (3) & $17.0(2.3-128)$ & 0.006 \\
\hline $3+$ lifetime disorders $^{b}$ & 6 & (10) & 0 & (0) & & \\
\hline Antisocial personality disorder & 36 & (60) & 27 & (45) & $1.7(0.9-3.4)$ & 0.133 \\
\hline
\end{tabular}


Table 4 Comparisons of current psychiatric treatment and current medication between male prisoners who made near-lethal suicide attempts (cases) and those who had not (controls)

\begin{tabular}{|c|c|c|c|c|c|c|c|}
\hline \multirow[b]{2}{*}{ Variable } & \multicolumn{2}{|c|}{ Cases $n=60$} & \multicolumn{2}{|c|}{ Controls $n=60$} & \multirow[b]{2}{*}{$\chi^{2}$} & \multirow[b]{2}{*}{ OR $(95 \% \mathrm{Cl})$} & \multirow[b]{2}{*}{$P$} \\
\hline & $n$ & (\%) & $n$ & (\%) & & & \\
\hline Current psychiatric treatment ${ }^{\mathrm{a}, \mathrm{b}}$ & 14 & (23) & 1 & (2) & 13.0 & & $<0.001$ \\
\hline Psychiatrist onlyc & 3 & (5) & 1 & (2) & & & \\
\hline Mental health nurse only ${ }^{c}$ & 6 & $(10)$ & 0 & (0) & & & \\
\hline Psychiatristc and mental health nurse ${ }^{c}$ & 4 & (7) & 0 & (0) & & & \\
\hline Psychologist onlyc & 1 & $(2)$ & 0 & $(0)$ & & & \\
\hline On medication & 40 & (67) & 13 & $(22)$ & & $28.0(3.8-206)$ & 0.001 \\
\hline Psychotropic medication $^{a}$ & 33 & (55) & 4 & (7) & 29.0 & & $<0.001$ \\
\hline Antidepressants ${ }^{a}$ & 22 & (37) & 4 & (7) & 18.0 & & $<0.001$ \\
\hline Mood stabilisers ${ }^{c}$ & 4 & (7) & 0 & (0) & & & \\
\hline Major tranquillisers ${ }^{a}$ & 11 & (18) & 0 & $(0)$ & & & \\
\hline Benzodiazepines and other sedatives & 17 & (28) & 2 & (3) & & $16.0(2.1-121)$ & 0.007 \\
\hline Medication for physical disorders & 12 & (20) & 4 & (7) & & $5.0(1.1-22.8)$ & 0.038 \\
\hline Opiates $^{\mathrm{C}}$ & 6 & (10) & 6 & (10) & & & \\
\hline Other ${ }^{\mathrm{C}}$ & 4 & (7) & 2 & (3) & & & \\
\hline
\end{tabular}

\section{Psychiatric treatment at the time of the interview}

There was a discrepancy between the number of cases experiencing a current episode of major depression $(52,87 \%)$ and those being prescribed antidepressants (22, 37\%). Research in the general population has also shown inconsistencies between the prevalence and treatment of depression, ${ }^{44,45}$ which is equally marked in people who have died by suicide. ${ }^{46}$ Nevertheless, unmet needs in relation to psychiatric illness in prison are considerable. ${ }^{47}$ The reasons for this may include inadequate methods of detection, scarce resources and limited staff training. ${ }^{48,49}$

Only $14(23 \%)$ cases were currently being seen by a mental health professional (psychiatrist, mental health nurse or psychologist), despite having made a serious suicide attempt less than 4 weeks previously. In addition to treatment for depression, unmet treatment needs for anxiety disorders, especially PTSD, social anxiety and panic disorder appear substantial.

\section{Strengths and limitations of the study}

Previous research investigating risk factors for suicide in prison has had a number of methodological limitations. These include the use of routinely collected cross-sectional data from variable quality prison and medical records ${ }^{13}$ that contain limited information on specific psychiatric diagnoses, particularly for controls. An advantage of this study was the ability to assess clinically the individual who undertook the act. In order to do this, we used the Mini International Neuropsychiatric Interview (MINI) for assessment of Axis I and Axis II diagnoses. However, although the MINI has several important strengths, including its validity, relatively brief administration time, acceptability to participants, ease of use and use in other prison research, ${ }^{28,29,31-33}$ the only Axis II diagnosis it includes is antisocial personality disorder, which was not found to be associated with near-lethal suicide attempts in this study. Further studies could seek to clarify the role of other personality disorders in near-lethal suicide attempts in prison since previous research is somewhat inconsistent. Limited previous research in prison has shown that personality disorders do not increase the risk of suicide ${ }^{50,51}$ whereas research in the community has shown that personality disorders (especially borderline, and possibly avoidant and schizoid) do increase risk of suicide. ${ }^{42,52}$

The prevalence rates in the control group for most psychiatric diagnoses generated by the MINI were approximately equivalent to those calculated in systematic reviews in the general male prison population. ${ }^{53}$ However, the rate of depression in the control group was higher than has been found in other studies using different diagnostic tools. ${ }^{53}$ This may be a consequence of the MINI overdiagnosing this disorder as other studies using it have also reported high rates of depression in prisoners. ${ }^{31,32}$

A disadvantage of face-to-face clinical assessment may include recall and self-presentation biases, and corroboration of information with key informants would have strengthened the study. ${ }^{12}$ Also, psychiatric diagnoses were made based on information obtained through interview usually some weeks after the nearlethal suicide attempt and may not necessarily equate to those present at the time of the act. Although our sample size allowed for testing of associations with the main psychiatric diagnoses, it was underpowered to test significance for less frequent disorders. We did not have access to data about how many of the control participants were registered as being at risk of suicide (i.e. had 'open' ACCT documents).

We included 19 prisons of differing types and categories, which should make the study's findings generalisable in England and Wales.

\section{Implications}

A number of potential implications arise from our findings. First, the high rate of psychiatric morbidity among suicidal prisoners suggests that many might benefit from alternative disposals, including hospital and community treatment orders. ${ }^{54,55}$ In addition, the marked difference in prevalence of psychiatric disorders between cases and controls contrasts with some expert opinion that has downplayed the role of mental illness in attempted and completed suicide in prisoners. ${ }^{56,57}$

Second, in a population where self-harming and suicide attempts, and mental health problems, are relatively common, identifying those most likely to take their own lives may be difficult. Nevertheless, the finding that only $24(40 \%)$ of the cases were identified as being 'at-risk' for suicide at the time of their attempt indicates that there may be scope for improving detection of those at risk of suicide, perhaps with a structured suicide screening tool. ${ }^{9,58}$ Our findings suggest that such an instrument should include questions regarding prisoners' history of psychiatric contact, previous self-harming and suicidal behaviour (especially if this occurred while in prison), and current 
psychiatric disorders. However, further research is needed to test the predictive value of such a tool and, in particular, to what extent false positives are identified. Furthermore, detection should be considered an ongoing process occurring at various stages of custody, rather than only at reception. This may be important if a prisoner's circumstances change, for example, if he is transferred or about to be released, since there is evidence of increased psychological distress before release ${ }^{59}$ and elevated risk of suicide shortly after release. ${ }^{60}$

Third, the discrepancy between the proportion of prisoners with psychiatric problems and those receiving pharmacological and/or psychological interventions suggests that in addition to better risk assessment, reviewing the treatment and management of common psychiatric disorders in at-risk prisoners should be considered. In the UK, responsibility for prison healthcare has recently been devolved to NHS primary care trusts (since April 2006). One possible area that may warrant further research is the efficacy and cost-effectiveness of interventions incorporating either pharmacological and psychosocial interventions or both. Any such research will be relevant to mental healthcare in prisons in other countries.

Although suicide and severe self-harming behaviours in prisoners are major problems in many countries, potentially modifiable risk factors have been little researched. We have attempted to assess the potential role of psychiatric disorders using a novel method, that of interviewing survivors of near-lethal suicide attempts, the findings of which should have relevance outside the UK.

Adrienne Rivlin, DPhil, Keith Hawton, DSC, Lisa Marzano, PhD, Seena Faze $\mathrm{MD}$, Centre for Suicide Research, University Department of Psychiatry, Warneford Hospital, Oxford, UK

Correspondence: Seena Fazel, MD, Centre for Suicide Research, University Department of Psychiatry, Warneford Hospital, Oxford OX3 7JX, UK.

Email: seena.fazel@psych.ox.ac.uk

First received 19 Jan 2010, final revision 29 Apr 2010, accepted 10 Jun 2010

\section{Funding}

The study was funded by the NHS Forensic Health R\&D Programme. K.H. is also supported by Oxfordshire and Buckinghamshire Mental Health NHS Foundation Trust and is a National Institute for Mental Health Research Senior Investigator.

\section{Acknowledgements}

We are grateful to Tunde Adeniji, Debra Baldwin, Pat Baskerville, and Jenny Rees of the Ministry of Justice Safer Custody and Offender Policy Group for their support and advice, Mary Piper of the Department of Health, Jo Borrill and Jo Paton for their assistance with the study, Adam Spriggs of the Ministry of Justice for providing control data, and all Area and Local Suicide Prevention Coordinators who helped with recruitment for the study. We also thank Karen Smith of the Centre for Statistics in Medicine for statistical assistance. Lastly, we thank all the prisoners who participated in this study.

\section{Appendix}

\section{Criteria for the identification of 'near-lethal' cases \\ Method}

Attempted hanging

Ligature use

Self-strangulation

Self-asphyxiation

Suffocation
Cutting

Stabbing

Wound aggravation

or insertion

Ingesting, inhaling, injecting

(a) level of consciousness

(b) biochemical abnormalities

Jumping from a considerable height

Other (e.g. setting fire to self) Case referral determined on a case-bycase basis

\section{References}

1 US Department of Health. National Strategy for Suicide Prevention: Goals and objectives for Action. US Department of Health and Human Services, 2001.

2 Department of Health. National Suicide Prevention Strategy for England and Wales. Department of Health, 2002.

3 Health Service Executive, Department of Health and Children. Reach Out: National Strategy for Action on Suicide Prevention 2005-2014. Health Service Executive, 2005

4 Associate Minister of Health. The New Zealand Suicide Prevention Strategy 2006-2016. Ministry of Health, 2006.

5 World Health Organization. Trencin Statement on Prisons and Mental Health. WHO, 2008.

6 Fazel S, Benning R, Danesh J. Suicides in male prisoners in England and Wales, 1978-2003. Lancet 2005; 366: 1301-2.

7 DuRand CJ, Burtka GJ, Federman EJ, Haycox JA, Smith JW. A quarter century of suicide in a major urban jail: implications for community psychiatry. Am J Psychiatry 1995; 152: 1077-80.

8 Fazel S, Grann M, Kling B, Hawton K. Prison suicide in 12 countries: an ecological study of 861 suicides during 2003-2007. Soc Psychiatry Psychiatr Epidemiol 2010; epub doi: 10.1007/s00127-010-0184-4.

9 Konrad N, Daigle MS, Daniel AE, Dear GE, Frottier P, Hayes LM, et al. Preventing suicide in prisons, Part 1. Crisis 2007; 28: 113-21.

10 Daigle MS, Daniel AE, Dear GE, Frottier $P$, Hayes LM, Kerkhof $A$, et al. Preventing suicide in prison, Part 2. Crisis 2007; 28: 122-30.

11 Fazel S, Cartwright J, Norman-Nott A, Hawton K. Suicide in prisoners: a systematic review of risk factors. J Clin Psychiatry 2008; 69: 1721-31.

12 Hawton K, Appleby L, Platt S, Foster T, Cooper J, Malmberg A, et al. The psychological autopsy approach to studying suicide: a review of methodological issues. J Affect Disord 1998; 50: 269-76.

13 Fruehwald $S$, Matschnig $T$, Koenig $F$, Bauer $P$, Frottier $P$. Suicide in custody: case-control study. Br J Psychiatry 2004; 185: 494-8.

14 Birmingham L, Mason D, Grubin D. Health screening at first reception into prison. J Forensic Psychiatr 1997; 8: 435-9.

15 Shaw J, Baker D, Hunt IM, Moloney A, Appleby L. Suicide by prisoners: national clinical survey. Br J Psychiatry 2004; 184: 263-7.

16 Marzano L, Rivlin A, Fazel S, Hawton K. Interviewing survivors of near-lethal self-harm: a novel approach for investigating suicide amongst prisoners. J Forensic Legal Med 2009; 16: 152-5.

17 Beautrais AL. Suicides and serious suicide attempts: two populations or one? Psychol Med 2001; 31: 837-45.

18 Daniel A, Fleming J. Serious suicide attempts in a state correctional system and strategies to prevent suicide. J Psychiatry Law 2005; 33: 227-47.

19 Rosen DH. The serious suicide attempt: five-year follow-up study of 886 patients. J Am Med AssoC 1976; 235: 2105-9.

20 Borrill J, Snow L, Medlicott D, Teers R, Paton J. Learning from near misses: interviews with women who survived an incident of severe self-harm. Howard J Crim Justice 2005; 44: 57-69.

21 Kresnow M, Ikeda RM, Mercy JA, Powell KE, Potter LB, Simon TR, et al. An unmatched case-control study of nearly lethal suicide attempts in 
Houston, Texas: research methods and measurements. Suicide Life Threat Behav 2001; 32: 7-19.

22 Hawton K, Harriss L, Hall S, Simkin S, Bale E, Bond A. Deliberate self-harm in Oxford, 1990-2000: a time of change in patient characteristics. Psychol Med 2003; 33: 987-96.

23 Beck AT, Schuyler D, Herman J. Development of suicidal intent scales. In The Predicion of Suicide (ed AT Beck, H Resnik, DJ Lettieri): 45-6. Charles, 1974.

24 Sheehan $D$, Lecrubier $Y$, Harnett-Sheehan $K$, Amorim $P$, Janavs J, Weiller $E$, et al. The Mini International Neuropsychiatric Interview (MINI): the development and validation of a structured diagnostic psychiatric interview. J Clin Psychiatry 1998; 59: 22-33.

25 American Psychiatric Association. Diagnostic and Statistical Manual of Mental Disorder (4th edn) (DSM-IV). APA, 1994.

26 World Health Organization. The ICD-10 Classification of Mental and Behavioural Disorders: Clinical Descriptions and Diagnostic Guidelines. WHO 1992.

27 Amorim $\mathrm{P}$, Lecrubier $\mathrm{Y}$, Weiller $\mathrm{E}$, Hergueta T, Sheehan D. DSM-III-R Psychotic disorders: procedural validity of the Mini International Neuropsychiatric Interview (MINI). Concordance and causes for discordance with the CIDI. Eur Psychiatry 1998; 13: 26-34.

28 Sheehan DV, Lecrubier $\mathrm{Y}$, Sheehan $\mathrm{KH}$, Janavs J, Weiller E, Keskiner A, et al. The validity of the Mini International Neuropsychiatric Interview (MINI) according to the SCID-P and its reliability. Eur Psychiatry 1997; 12: 232-41.

29 Lecrubier $Y$, Sheehan DV, Weiller E, Amorim P, Bonora I, Sheehan KH, et al. The Mini International Neuropsychiatric Interview (MINI). A short diagnostic structured interview: reliability and validity according to the CIDI. Eur Psychiatry 1997; 12: 224-31.

30 Spitzer RL, Williams JBW, Gibbon M, First MB. Structured Clinical Interview for $D S M-I I I-R$. American Psychiatric Press, 1990.

31 Black DW, Arndt S, Hale N, Rogerson R. Use of the Mini International Neuropsychiatric Interview (MINI) as a screening tool in prisons: results of a preliminary study. J Am Acad Psychiatry Law 2004; 32: 158-62.

32 Gunter TD, Arndt S, Wenman G, Allen J, Loveless P, Sieleni B, et al. Frequency of mental and addictive disorders among 320 men and women entering the lowa prison system: use of the MINI-Plus. J Am Acad Psychiatry Law 2008; 36: 27-34.

33 Falissard B, Loze J-Y, Gasquet I, Duburc A, de Beaurepaire C, Fagnani F, et al. Prevalence of mental disorders in French prisons for men. BMC Psychiatry 2006; 6: 33

34 Mickey RM, Greenland S. The impact of confounder selection criteria on effect estimation. Am J Epidemiol 1989; 129: 125-37.

35 Tong S, Lu Y. Identification of confounders in the assessment of the relationship between lead exposure and child development. Ann Epidemiol 2001; 11: 38-45.

36 HM Prison Service. Suicide and Self-Harm Prevention. HM Prison Service, 2007.

37 Harriss L, Hawton $\mathrm{K}$, Zahl D. Value of measuring suicidal intent in the assessment of people attending hospital following self-poisoning or selfinjury. Br J Psychiatry 2005; 186: 60-6.

38 Harris EC, Barraclough B. Suicide as an outcome for mental disorders: a meta-analysis. Br J Psychiatry 1997; 170: 205-28.
39 Conner KR, Duberstein PR. Predisposing and precipitating factors for suicide among alcoholics: empirical review and conceptual integration. Alcohol Clin Exp Res 2004; 28: S6-17.

40 Baillargeon J, Penn JV, Thomas CR, Temple JR, Baillargeon G, Murray OJ. Psychiatric disorders and suicide in the nation's largest state prison system. J Am Acad Psychiatry Law 2009; 37: 188-93.

41 Goff A, Rose E, Rose S, Purves D. Does PTSD occur in sentenced prison populations? A systematic literature review. Crim Behav Ment Health 2007 17: $152-62$

42 Duberstein PR, Conwell Y. Personality disorders and completed suicide: a methodological and conceptual review. Clin Psychology 1997; 4: 359-76.

43 Jenkins $R$, Bhugra $D$, Meltzer $H$, Singleton $N$, Bebbington $P$, Brugha $T$, et al. Psychiatric and social aspects of suicidal behaviour in prisons. Psychol Med 2005; 35: 257-69.

44 Steffens DC, Skoog I, Norton MC, Hart AD, Tschanz JT, Plassman BL, et al. Prevalence of depression and its treatment in an elderly population: the Cache County study. Arch Gen Psychiatry 2000; 57: 601-7.

45 Kessler RC, Demler O, Frank RG, Olfson M, Pincus HA, Walters EE, et al. Prevalence and treatment of mental disorders, 1990 to 2003. N Engl J Med 2005; 352: 2515-23.

46 Lonnqvist J. Psychiatric aspects of suicidal behaviour. In Suicide and Attempted Suicide (ed K Hawton, K van Heeringen): 107-20. John Wiley \& Sons, 2000.

47 Fryers T, Brugha T, Grounds A, Meltzer D. Severe mental illness in prisoners. BMJ 1998; 317: 1025-6.

48 Birmingham L, Wilson S, Adshead G. Prison medicine: ethics and equivalence. Br J Psychiatry 2006; 188: 4-6.

49 Bluglass R. Recruitment and training of prison doctors. BMJ 1990; 301 249-50.

50 National Association for the Care and Resettlement of Offenders. Suicide in Prison. NACRO, 1990.

51 Phillips M. A Study of Suicides and Attempted Suicides at HMP Brixton, 1973-1983. Home Office, 1986.

52 Lieb K, Zanarini MC, Schmahl C, Linehan M, Bohus M. Borderline personality disorder. Lancet 2004; 364: 453-61.

53 Fazel S, Danesh J. Serious mental disorder in 23000 prisoners: a systematic review of 62 surveys. Lancet 2002; 359: 545-50.

54 Reed J. Mental health care in prisons. Br J Psychiatry 2003; 182: 287-8.

55 Birmingham L. Diversion from custody. Adv Psychiatr Treat 2001; 7: 198-207.

56 Liebling A. Suicides in Prison. Routledge, 1992.

57 Groves A. Blood on the walls: self-mutilation in prisons. Aust NZ J Criminol 2004; 37: 49-64.

58 Frottier $\mathrm{P}$, Koenig $\mathrm{F}$, Seyringer $\mathrm{M}$, Matschnig $\mathrm{T}$, Fruehwald $\mathrm{S}$. The distillation of "VISCI": towards a better identification of suicidal inmates. Suicide Life Threat Behav 2009; 39: 376-84.

59 Bukstel LH, Kilmann PR. Psychological effects of imprisonment on confined individuals. Psychol Bull 1980; 85: 469-93.

60 Pratt D, Piper M, Appleby L, Webb R, Shaw J. Suicide in recently released prisoners: a population-based cohort study. Lancet 2006; 368: 119-23. 